\title{
Gas Chromatographic-Selected Ion Monitoring-Mass Spectrometric Determination of Cigarette Mainstream Smoke Components with Sensory Attributes*
}

\author{
by \\ W.M. Coleman, III. \\ R.J. Reynolds Tobacco Company, P.O. Box 1487, Winston-Salem, NC 27102-1487, USA
}

\section{SUMMARY}

\begin{abstract}
A new method has been developed that detects significant quantitative differences in the amounts of pyrazines, pyridines, furfurals, carboxylic acids, $\beta$-damascenone, sclareolide, and megastigmatrienones in the mainstream smoke of a series of five commercial cigarettes. This new quantitative method is based on the gas chromatographic-selected ion monitoring-mass spectrometric (GC-SIM-MS) determination of the selected smoke constituents. The accuracy and precision of the approach were well within acceptable parameters with the majority of cases relative standard deviation (RSD) values consistently around 5\%. Sample preparation was simple requiring only the dissolution of the trapped particulate material in a known volume of methanol followed by injection of this clear dark colored solution into the gas chromatograph. This approach represents an advance in the technology in terms of higher sample throughput and less sample workup. Certain products demonstrated consistent trends in concentration of specific chemical classes. The mainstream smoke from a University of Kentucky reference cigarette, 2R4F, was included for reference purposes. These results are applicable in the overall evaluation of the components responsible for the taste associated with cigarette products. [Beitr. Tabakforsch. Int. 21 (2004) 175-183]
\end{abstract}

\section{ZUSAMMENFASSUNG}

Eine neue Methode wurde entwickelt, mit der sich quantitativ signifikante Unterschiede bei den Mengen an Pyrazinen, Pyridinen, Furfuralen, Carbonsäuren, $\beta$-Damascenone, Sclareoliden und Megastigmatrienonen im Hauptstromrauch von fünf handelsüblichen Zigaretten erfassen lassen. Diese neue quantitative Methode basiert auf einer gaschromatographisch-massenspektrometrischen Bestim- mung mit „Selected ion monitoring” (GC-SIM-MS) der ausgewählten Rauchbestandteile. Die Richtigkeit und Präzision des Ansatzes bewegen sich in einem annehmbaren Schwankungsbereich, wobei die relative Standardabweichung (RSD) überwiegend bei $5 \%$ liegt. Die Probenaufbereitung war einfach und erforderte lediglich die Lösung der aufgefangenen Partikel in einer vorgegebenen Methanolmenge und nachfolgende Einspritzung dieser klaren, dunklen Lösung in einen Gaschromatographen. Dieser Ansatz stellt wegen des höheren Probendurchsatzes und geringerer Probenaufbereitung einen Entwicklungsfortschritt dar. Bei einigen Zigarettentypen wurden konsistente Trends bezüglich der Konzentration spezifischer chemischer Substanzklassen festgestellt. Der Hauptstromrauch der Referenzzigarette 2R4F der University of Kentucky wurde zum Vergleich herangezogen. Die Ergebnisse sind für die allgemeine Bewertung der Rauchkomponenten von Bedeutung, die für den Geschmack der Zigaretten verantwortlich sind. [Beitr. Tabakforsch. Int. 21 (2004) 175-183]

\section{RESUME}

Une nouvelle méthode analytique a été développée pour détecter des différences quantitatives significatives dans la teneur des pyrazines, pyridines, furfurals, acides carboxyliques, $\beta$-damascénone, sclariolide et mégastigmatrièneones dans la fumée principale d'une série de cinq marques de cigarettes du marché. Cette nouvelle méthode quantitative est basée sur le dosage des composants de la fumée de tabac par chromatographie en phase gazeuse-spectrométrie de masse en mode de suivi d'ions sélectionnés (GC-SIMMS). La précision et la fiabilité de cette approche sont acceptables avec des valeurs d'écart type relatif pour la plupart des composants d'environ 5\%. La préparation des échantillons est simple, nécessitant seulement la dissolution 
des particules piégées dans du méthanol dans un volume connu, suivi de l'injection de cette solution clair foncée dans le chromatographe à gaz (GC). Cette approche constitue une avance technologique en augmentant la quantité des échantillons traités et en réduisant la préparation des échantillons. Chez certains produits une concentration de substances de classes chimiques spécifiques a été observée. La fumée principale de la cigarette de référence Kentucky $2 \mathrm{R} 4 \mathrm{~F}$ a été évaluée pour des raisons de comparaison. Ces résultats peuvent être appliqués pour l'évaluation des composants responsables du goût associés aux produit de cigarettes. [Beitr. Tabakforsch. Int. 21 (2004) 176-183]

\section{INTRODUCTION}

Commercial cigarettes are made by blending various types of tobacco leaves and reconstituted/processed tobacco materials. Flavor ingredients are sometimes used, generally in the sub ppm range, to complement the subjective characteristics of the tobacco smoke. In a number of cases, flavor compounds transfer unchanged into the mainstream smoke (1). In addition, tobacco smoke generated from a tobacco burning cigarette is a very complex matrix containing hundreds or even thousands of individual compounds each having an associated aroma/flavor characteristic and a corresponding aroma or taste threshold value (2-9). A number of the components identified in tobacco smoke have well established aroma characteristics and aroma thresholds $(10,11)$. The pathways by which these compounds are formed have been the subject of a variety of investigations some having specific foci (9-20). Classes of compounds found in tobacco smoke having powerful sensory attributes at relatively low levels include pyridines, pyrazines, furfurals, carboxylic acids, and carotenoid degradation products such as $\beta$-damascenone and megastigmatrienone isomers $(10,11)$. The approximate levels of these classes of compounds in tobacco smoke have concentration ranges in the area of multiple $\mu \mathrm{g} / \mathrm{cig}(1-10,12)$. With aroma and flavor threshold values for some of these compound classes in the ppm to ppb range, these classes of compounds posses the capability of having significant sensory impact on cigarette products.

Thus, an analytical method, having a simple sample preparation protocol, has been developed that has the capability to provide quantitative determination of numerous targeted compounds of differing functionality in the mainstream smoke condensate. In this work the details of the sample collection and analytical protocol will be presented. The method is based on the gas chromatographic-selected ion monitoring-mass spectrometric (GC-SIM-MS) determination of selected mainstream smoke constituents having sensory attributes. The targeted compound classes include pyridines, pyrazines, carboxylic acids, furfurals, and carotenoid degradation products such as megastigmatrienones and $\beta$-damascenone. For reference purposes, a University of Kentucky reference cigarette, $2 \mathrm{R} 4 \mathrm{~F}$, was included in the study. This product also serves as a quality control sample in the analysis scheme in that multiple analyses of the smoke from the $2 \mathrm{R} 4 \mathrm{~F}$ product were conducted throughout the entire timeframe of the experiments.

\section{EXPERIMENTAL}

\section{Sample description and preparation}

The five products, Products A through E, were obtained commercially and the reference product, 2R4F, was obtained from the Tobacco and Health Research Institute of the University of Kentucky. The products were conditioned under Federal Trade Commission (FTC) parameters (20). The mainstream smoke condensate of 40 cigarettes from three repetitive smokings of each product was captured on a glass tube by electrostatic precipitation (ESP) by means of a Borgwaldt 20 port rotary smoking machine. The products were smoked to a butt length of 37 mm using a $35 \mathrm{cc}$ puff, every $60 \mathrm{~s}$ of 2 -s duration. The condensate from the ESP tube was collected by washing with $20 \mathrm{~mL}$ of methanol (Burdick and Jackson, Muskegon, MI). The samples were placed in GC autosampler vials and stored at $-80{ }^{\circ} \mathrm{C}$ until ready for analysis. Most often the samples were analyzed immediately after smoking. The smokings were performed on three separate days. Wet total particulate matter (WTPM) was gravimetrically determined by accurately determining the mass of particulate matter collected on the ESP tube due to the smoking of 40 cigarettes.

\section{Standards preparation}

Standards were prepared by dissolving known amounts of each compound in known volumes of methanol. Pyrazine, methylpyrazine, 2,6-dimethylpyrazine, ethylpyrazine, 2,3dimethylpyraine, 2-ethyl-6-methylpyrazine, 2-ethyl-5methylpyrazine, trimethylpyrazine, 2,5-dimethyl-3-ethylpyrazine, 2,6-dimethyl-3-ethylpyrazine, and tetramethylpyrazine, were obtained from Pyrazine Specialities, Inc., Atlanta, GA. The acids, 2-methylpropionic acid, 3-methylbutyric acid, and 3-methylpentanoic acid, the pyridines (pyridine, 2-methylpyridine, 2,6-dimethylpyridine, 2-ethylpyridine, 3-methylpyridine, 4-methylpyridine, 2,5-dimethylpyridine, 2,4-dimethylpyridine, 2,3-dimethylpyridine, 2,4,6-trimethylpyridine, 3-ethylpyridine, 4-ethylpyridine, 5-ethyl-2-methylpyridine, 2,3,5-trimethylpyridine, 3-butylpyridine), cyclotene, furfural, and 5-methylfurfural were obtained from Aldrich Chemical Company, Milwaukee, WI. Beta-damascenone was obtained from Firmenich Inc., Princeton, NJ and the mixture of four megastigmatrienones was obtained from IFF, Inc., Dayton, NJ. Sclareolide was obtained from the Avoca Division of R.J. Reynolds Tobacco Company. All reagents were used as received and purities were greater than $95 \%$ in all cases.

\section{Safety note}

Most of the compounds employed in this study are toxic in the neat form and may enter the body by inhalation or absorption through the skin. Effects of over exposure include nausea, irritation, and burning. Caution must be taken when working with the neat compounds or concentrated solutions. All solution preparations should be performed in an approved fume hood. Appropriate chemical-resistant gloves should be worn. 
Table 1. Gas chromatography-mass spectrometry operating conditions

\begin{tabular}{ll}
\hline Parameters & Conditions \\
\hline System configuration & $\begin{array}{l}\text { Hewlett Packard (HP) 6890 GC } \\
\text { equipped with a 5973 mass selec- } \\
\text { tive detector and an autosampler } \\
\text { DB-WAXetr, 30 m, 0.25 mm i.d., }\end{array}$ \\
Column & $0.25 \mu \mathrm{m}$ film thickness \\
Injection port temp. & $250{ }^{\circ} \mathrm{C}$ \\
Injection & Split $10: 10$ \\
Inlet pressure & Constant flow, $1 \mathrm{~mL} / \mathrm{min}$ \\
Column oven initial temp. & $45^{\circ} \mathrm{C}$ \\
Column oven initial time & $0.50 \mathrm{~min}$ \\
Column oven ramp rate & $5^{\circ} \mathrm{C} / \mathrm{min}$ \\
Column oven final temp. & $250^{\circ} \mathrm{C}$ \\
Column oven final time & $8.5 \mathrm{~min}$ \\
MS transfer line temp. & $250^{\circ} \mathrm{C}$ \\
Mass spectral databases & $\mathrm{NBS}$, Wiley \\
Mass spectrometer & Selected ion monitoring, $70 \mathrm{eV}$ \\
\multicolumn{1}{c}{ configuration } & \\
\hline
\end{tabular}

Table 2. Compounds, selected ions and retention times

\begin{tabular}{lccc}
\hline Compound & SIM ions & RT, min \\
\hline Pyrazine & 80 & 7.86 \\
Methylpyrazine & 94 & 9.09 \\
2,6-Dimethylpyrazine & 107,108 & 10.56 \\
Ethylpyrazine & 107,108 & 10.74 \\
2,3-Dimethylpyrazine & 107,108 & 11.01 \\
2-Ethyl-6-methylpyrazine & 121,122 & 11.97 \\
2-Ethyl-5-methylpyrazine & 121,122 & 12.12 \\
Trimethylpyrazine & 121,122 & 12.39 \\
2,5-Dimethyl-3-ethylpyrazine & $121,135,136$ & 13.29 \\
2,6-Dimethyl-3-ethylpyrazine & $121,135,136$ & 13.69 \\
Furfural & 95,96 & 14.06 \\
5-Methylfurfural & 109,110 & 16.69 \\
2-Methylpropionic acid & 73,88 & 16.79 \\
3-Methylbutyric acid & 60,87 & 19.01 \\
3-Methylpentanoic acid & 60,87 & 21.82 \\
B-Damascenone & $69,121,190$ & 22.20 \\
Megastigmatrienone I & $147,175,190$ & 28.89 \\
Megastigmatrienone II & $147,175,190$ & 29.67 \\
Megastigmatrienone III & $147,175,190$ & 30.92 \\
Megastigmatrienone IV & $147,175,190$ & 31.41 \\
Sclareolide & $123,235,95$ & 42.61 \\
\hline
\end{tabular}

\section{Gas chromatography-mass spectrometry analysis conditions}

The gas chromatography-selected ion monitoring-mass spectrometry parameters listed in Table 1, were applied to the analysis of each sample. The average response of one injection of each sample from three separate smokings was used to calculate concentration and percent relative standard deviation (\%RSD).

Two separate GC-MS systems under the same conditions and same column type were employed in the overall approach. This tactic was employed to facilitate assignment
Table 3. Compounds, selected ions and retention times

\begin{tabular}{lc|c}
\hline Compound & SIM ions & RT, min \\
\hline Pyridine & 79,52 & 6.79 \\
2-Methylpyridine & 93,78 & 7.55 \\
2,6-Dimethylpyridine & 107,106 & 8.30 \\
2-Ethylpyridine & 106,107 & 9.12 \\
3-Methylpyridine & 93,92 & 9.34 \\
4-Methylpyridine & 93,92 & 9.50 \\
2,5-Dimethylpyridine & 107,106 & 10.13 \\
2,4-Dimethylpyridine & 107,106 & 10.36 \\
2,3-Dimethylpyridine & 107,106 & 10.97 \\
2,4,6-Trimethylpyridine & 121,120 & 11.17 \\
3-Ethylpyridine & 92,107 & 11.48 \\
4-Ethylpyridine & 107,106 & 11.77 \\
5-Ethyl-2-methylpyridine & 106,121 & 12.28 \\
2,3,5-Trimethylpyridine & 121,120 & 13.79 \\
3-Butylpyridine & 92,135 & 16.32 \\
Cyclotene & 112,69 & 21.96 \\
\hline
\end{tabular}

and collection of selected ions within relatively narrow retention time windows as well as to improve overall sample analysis time.

\section{Calibration and component yield calculations}

Calibration curves for each compound or in the case of the megastigmatrienones (a four isomer mixture) were prepared from serial dilutions of three concentrations in the general range of 100,10 and $1 \mu \mathrm{g} / \mathrm{mL}$. A minimum of four standard values was employed for the generation of each calibration curve. The mass spectrum of each component was obtained and from the spectrum was taken the major ion and at least one confirmatory ion whenever possible. To confirm the identity of those components having only one selected ion, standard additions to the smoke matrix were performed periodically and response factors calculated. In addition, the chromatograms of smoke samples fortified with standards were closely examined for the appearance of peaks not associated with the analytes of interest or for unexpected shifts in retention times.

The selected ions served as the ions employed in the SIM mode. The response from these selected ions was used to calculate component concentrations. A list of compounds, their selected ions, and retention times (RT) can be found in Tables 2 and 3. One GC-MS system was used for the analytes in Table 2 while a second GC-MS system was used for the analytes in Table 3. Calibration standards were analyzed periodically throughout the entire experiment to guard against instrument drift, sample evaporation and partial or incomplete injections.

Multiple injections, 6 , of the standard solutions yielded a $\%$ RSD variation of approximately $2 \%$ for each component. Linear equations were derived from the plots of concentration vs. selected ion abundance, having forced the line through a zero intercept. In all cases the $R^{2}$ values for the linear curves were greater than 0.9998 with all points falling either on or close to the calibration line. Calculations of the yield per cigarette were made by multiplying the methanol concentration determined from the calibration 


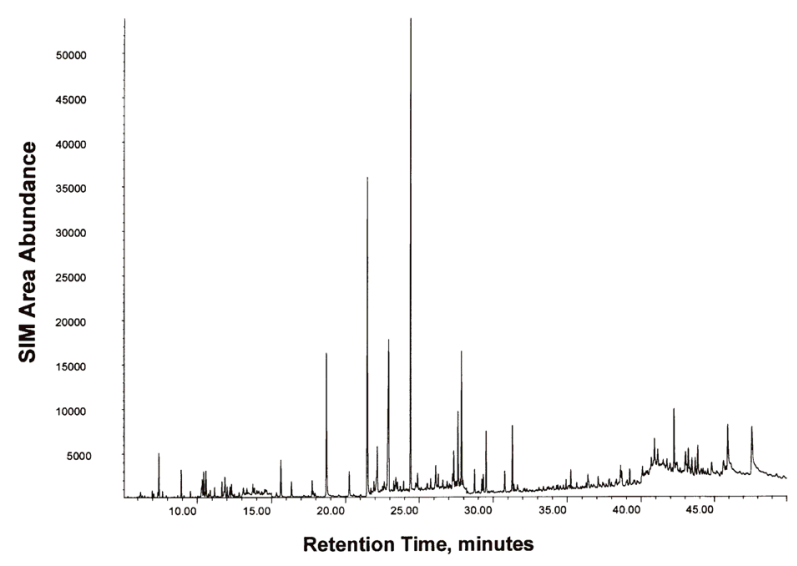

Figure 1. SIM chromatogram of mainstream smoke from Product E.

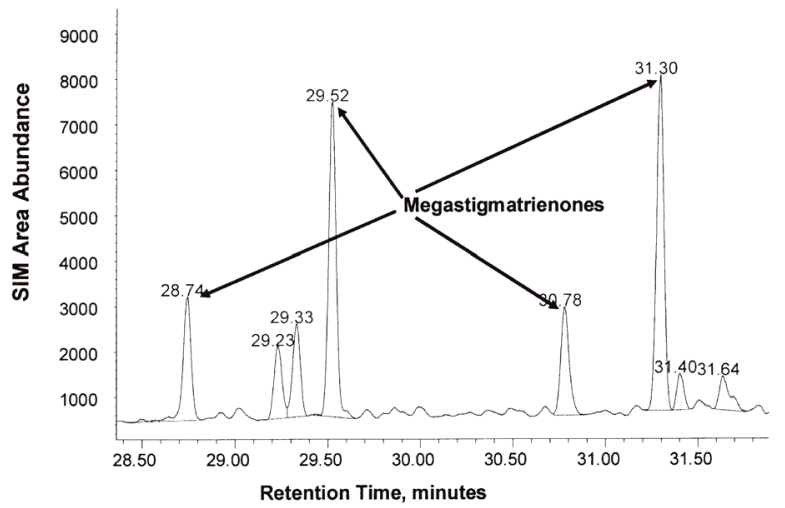

Figure 2. SIM chromatogram of megastigmatrienone section of Product $E$

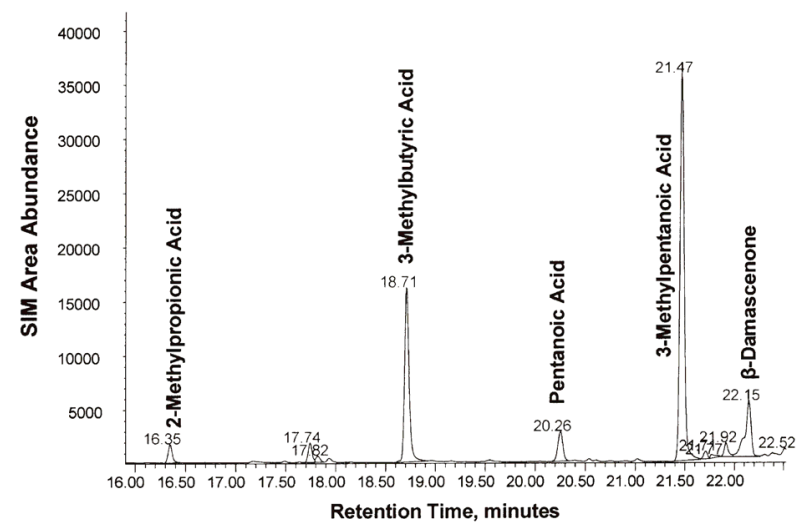

Figure 3. SIM chromatogram of acid/ $\beta$-damascenone section of Product E

curve by the extraction volume of $20 \mathrm{~mL}$ followed by dividing this total yield by the number of cigarettes, 40 . The \%RSD for the three injections was found to be compound specific, but was consistently between $5 \%$ and $10 \%$. Calculations of the yield on a ng/mg WTPM basis were made by dividing the yield per cigarette by the mg WTPM value. This value was then adjusted from a $\mu \mathrm{g} / \mathrm{mg}$ WTPM value to a ng/mg WTPM by multiplying by 1000 .
For the purposes of these analyses, the detection limit for each analyte was set to the lowest calibration standard, approximately $1 \mathrm{ng} / \mu \mathrm{L}$. This value also served as the limit of quantitation for all analytes.

\section{RESULTS AND DISCUSSION}

Tobacco smoke is a very complex matrix containing at least 4000 compounds (21). Among those classes of compounds having significant sensory attribute contributions to tobacco smoke are pyridines, pyrazines, carboxylic acids, furfurals, and carotenoid degradation products such as megastigmatrienones, $\beta$-damascenone, and sclareolide. Concentrations for these classes of compounds have been available for some time but yet no single analytical method has been developed capable of providing quantitative data on the concentrations of a wide array of these components in one procedure (10). The concentration ranges obtained for these compound classes vary from less than 1 to more than 1000 $\mu \mathrm{g} / \mathrm{cig}$ depending on the type and design of the cigarette rod.

The compounds targeted for these analyses were selected based in part on their documented sensory characteristics as well as their olfactory detection thresholds. For example, pyrazines have been shown to possess powerful sensory characteristics such as toasted, roasted, nutty, sweet, breadlike and peanut-like. In addition, their threshold levels span a range in concentration from multiple ppm to unit ppb levels as a function of structure $(15,23,24)$. The selected carboxylic acids, 2-methylpropionic, 3-methylbutyric and 3-methylpentanoic acid, are noted for their sweaty sock and cheese-like notes at ppb levels $(10,25)$. Likewise, pyridines have been described as having green, sweet, and tobaccolike notes at ppm levels (10). The carotenoid degradation compounds such as the megastigmatrienones, $\beta$-damascenone and sclareolide have powerful cedar, woody notes at the ppb level (10). The furfurals have been described as having sweet-spicy to caramellic notes in the ppm range (11).

Thus, the first stage or challenge in the development of this target compound approach involved the development of an adequate separation of all of the compounds of interest, preferably employing one column type and one separation set of conditions. After experiments with selected column types including, FFAP, DB-5, DB-1701, coupled with column oven variations, a DBWAXetr column was selected which provided baseline separation for the ingredients listed in Tables 2 and 3. The DBWax style column had previously been effectively used for the separation of tobacco materials (22). The SIM chromatogram, employing the DBWaxetr column, from the mainstream smoke from Product E is shown in Figure 1. The SIM chromatograms from the other products were very similar qualitatively. Portions of the SIM chromatogram have been expanded in Figures 2 to 4 to indicate the types of separation obtained and to provide some information on the chromatographic signal to noise conditions obtained for the analyses. Baseline separation of all selected components with acceptable signal to noise performance was possible with an overall injection to injection turnaround time of approximately one hour. 


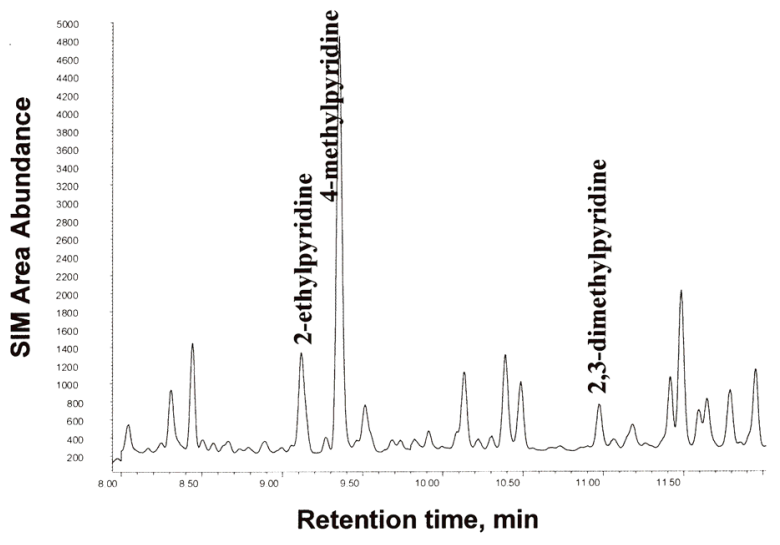

Figure 4. SIM chromatogram of a portion of the pyridine section of Product $E$

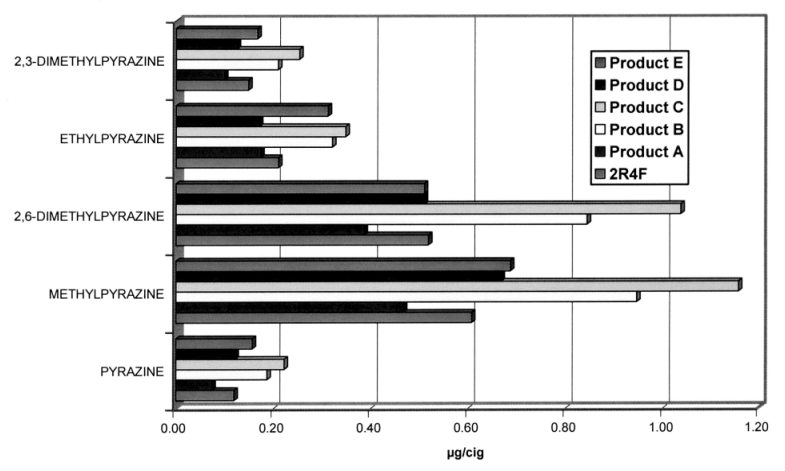

Figure 5. Concentration, $\mu \mathrm{g} / \mathrm{cig}$, of targeted pyrazines in the mainstream smoke of selected products

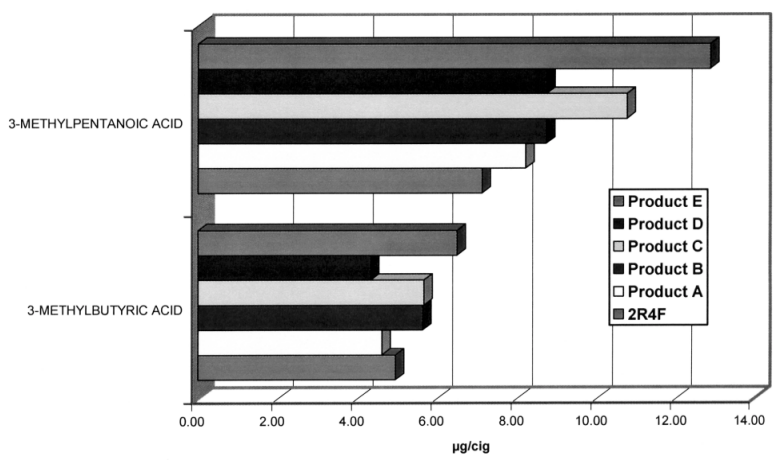

Figure 6. Concentration, $\mu \mathrm{g} / \mathrm{cig}$, of targeted carboxylic acids in the mainstream smoke of selected products

Smoke samples from the six products were generated as described above. One injection of each sample from three smokings was made and \%RSD calculations were performed on each component of interest. The values for each component, $\mu \mathrm{g} / \mathrm{cig}$, within each sample and \%RSD values are listed in Table 4.

The next step in the evaluation centered on an examination of the data in Table 4 for the presence of any significant trends in the concentration of the selected analytes as a function of product type. A portion of the data can be more

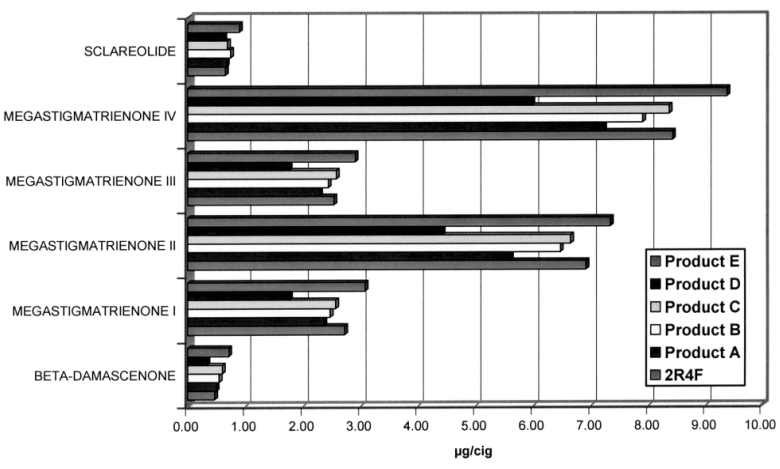

Figure 7. Concentration, $\mu \mathrm{g} / \mathrm{cig}$, of targeted carotenoid degradation compounds in the mainstream smoke of selected products

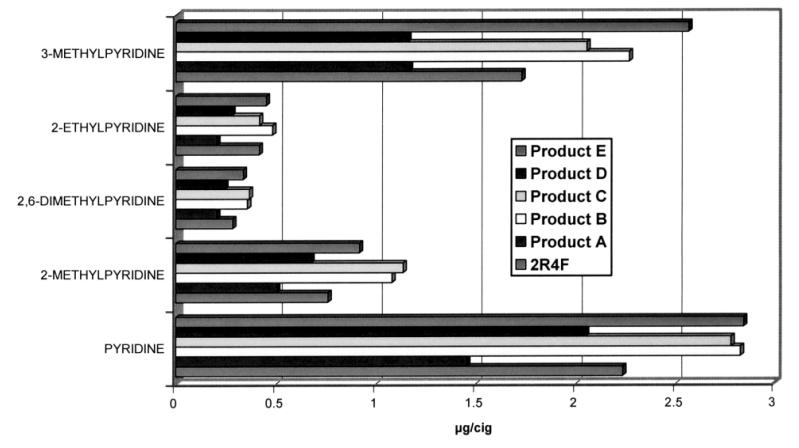

Figure 8. Concentration, $\mu \mathrm{g} / \mathrm{cig}$, of targeted pyridines in the mainstream smoke of selected products

conveniently examined when plotted as in Figures 5 to 8 . From an evaluation of the data in Table 4, coupled with the visual cues available in Figures 5 to 8, several conclusions can be drawn from the data: 1) Product $\mathrm{C}$ had consistently the highest levels of pyrazines while Product A was consistently the lowest; 2) methylpyrazine and 2,6dimethylpyrazine were the dominant pyrazines detected, however, from a sensory/threshold perspective, pyrazines with four carbons attached, i.e., dimethylethylpyrazines possess much lower threshold values than the pyrazines with 1 or 2 carbons attached, i.e., methyl and dimethylpyrazines; 3) Product E had the highest levels of the targeted carboxylic acids; 4) pyridine, 3-methylpyridine and 3-ethylpyridine were the dominant pyridines detected; 5) Product A was consistently the lowest in pyridines; 6) Product D was consistently the lowest in carotenoid degradation compounds, while Product E was consistently the highest; 7) Product E had the highest levels of furfurals and cyclotene.

To this point in the discussion of the results, the data have focused on the yield of targeted components on a per cigarette basis. While comparisons on a per cigarette basis are suitable in their own right and acceptable for comparisons, an assessment of the yields of these components as a function of cigarette yield, i.e., WTPM, is also applicable. The average WTPM values (mg/cig) for the three smokings of Product A, Product B, Product C, Product D, Product E, and 2R4F, were 9.1, 12.1, 12.5, 10.4, 9.5, and 11.0, respectively.

The data clearly indicate a considerable range in WTPM, thus the comparative yields of the selected analytes as a 


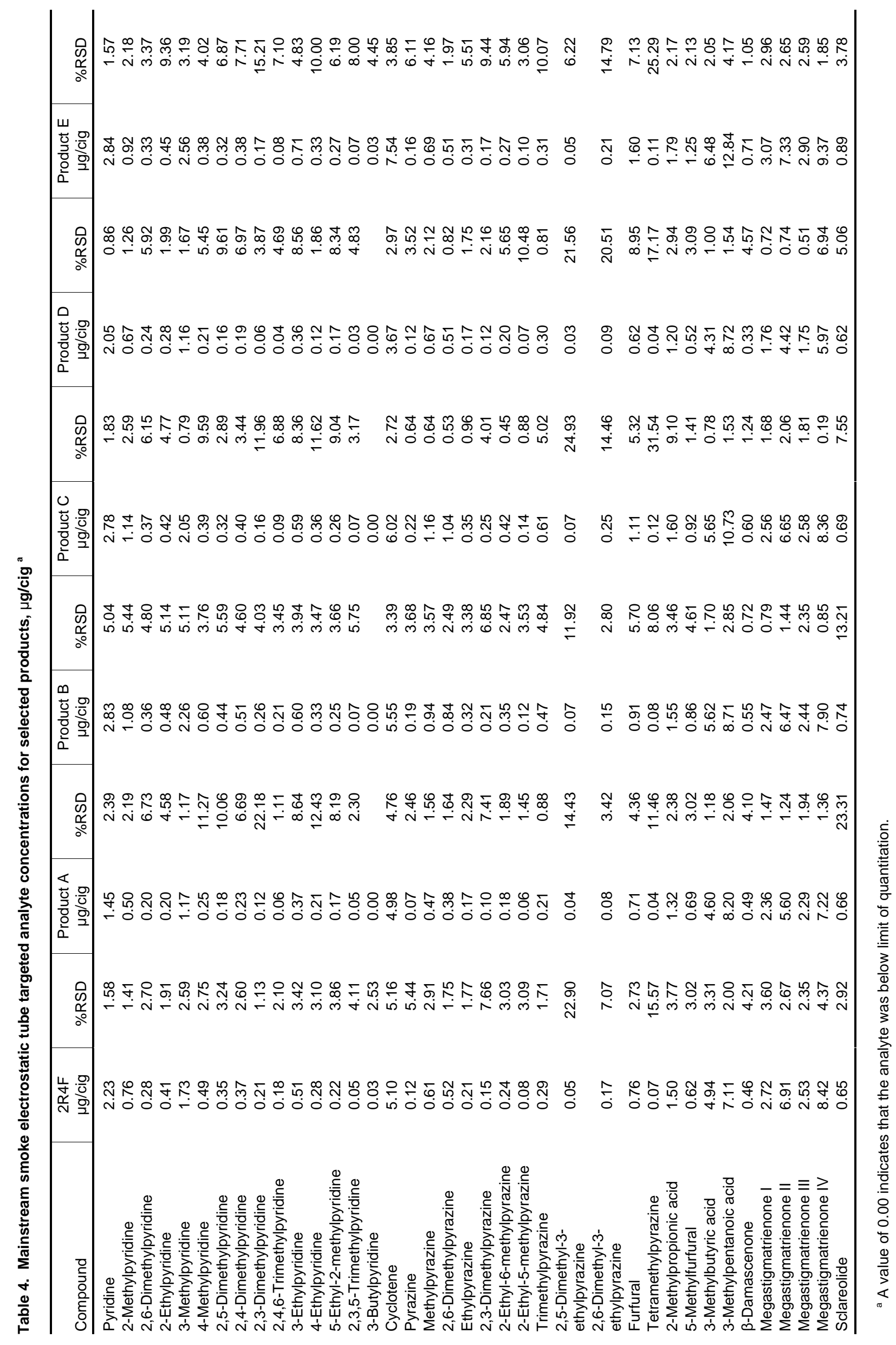


Table 5. Mainstream smoke electrostatic tube targeted analyte concentrations for selected products, $\mathrm{ng} / \mathrm{mg} \mathrm{WTPM}^{\text {a }}$

\begin{tabular}{|c|c|c|c|c|c|c|}
\hline Compound & 2R4F & Product A & Product B & Product C & Product D & Product E \\
\hline Pyridine & 202.80 & 160.38 & 233.79 & 221.98 & 196.08 & 300.57 \\
\hline 2-Methylpyridine & 68.90 & 55.30 & 89.23 & 90.66 & 64.47 & 96.90 \\
\hline 2,6-Dimethylpyridine & 25.69 & 22.37 & 29.45 & 29.20 & 23.18 & 35.32 \\
\hline 2-Ethylpyridine & 37.67 & 22.42 & 39.76 & 33.21 & 26.56 & 47.47 \\
\hline 3-Methylpyridine & 156.97 & 128.57 & 187.23 & 163.93 & 110.89 & 270.98 \\
\hline 4-Methylpyridine & 44.28 & 27.14 & 49.34 & 31.26 & 19.71 & 40.02 \\
\hline 2,5-Dimethylpyridine & 31.69 & 19.37 & 36.05 & 25.23 & 15.48 & 33.70 \\
\hline 2,4-Dimethylpyridine & 33.32 & 24.95 & 42.13 & 31.81 & 18.38 & 39.76 \\
\hline 2,3-Dimethylpyridine & 19.42 & 13.33 & 21.51 & 13.05 & 6.06 & 17.82 \\
\hline 2,4,6-Trimethylpyridine & 16.14 & 6.26 & 17.33 & 7.47 & 4.11 & 8.60 \\
\hline 3-Ethylpyridine & 46.03 & 41.10 & 50.04 & 47.13 & 34.64 & 74.61 \\
\hline 4-Ethylpyridine & 25.43 & 22.92 & 27.66 & 28.57 & 11.09 & 34.84 \\
\hline 5-Ethyl-2-methylpyridine & 20.25 & 19.26 & 20.90 & 21.08 & 16.65 & 28.26 \\
\hline 2,3,5-Trimethylpyridine & 4.81 & 5.04 & 5.59 & 5.44 & 3.22 & 7.34 \\
\hline 3-Butylpyridine & 3.15 & 0.00 & 0.00 & 0.00 & 0.00 & 3.12 \\
\hline Cyclotene & 463.68 & 549.57 & 458.91 & 481.08 & 351.32 & 797.63 \\
\hline Pyrazine & 10.79 & 8.14 & 15.42 & 17.71 & 11.59 & 16.49 \\
\hline Methylpyrazine & 55.13 & 51.51 & 78.13 & 92.36 & 63.91 & 72.54 \\
\hline 2,6-Dimethylpyrazine & 47.06 & 42.47 & 69.75 & 82.76 & 48.79 & 53.82 \\
\hline Ethylpyrazine & 19.02 & 19.11 & 26.45 & 27.77 & 16.31 & 32.92 \\
\hline 2,3-Dimethylpyrazine & 13.45 & 10.90 & 17.27 & 20.15 & 11.94 & 17.57 \\
\hline 2-Ethyl-6-methylpyrazine & 21.56 & 20.16 & 28.78 & 33.21 & 19.37 & 28.43 \\
\hline 2-Ethyl-5-methylpyrazine & 7.39 & 6.72 & 9.77 & 11.52 & 6.45 & 10.28 \\
\hline Trimethylpyrazine & 26.68 & 23.64 & 39.28 & 48.50 & 28.28 & 32.63 \\
\hline 2,5-Dimethyl-3-ethylpyrazine & 4.44 & 4.03 & 6.09 & 5.83 & 3.18 & 5.16 \\
\hline 2,6-Dimethyl-3-ethylpyrazine & 15.59 & 9.15 & 12.55 & 20.07 & 9.02 & 22.19 \\
\hline Furfural & 68.78 & 78.10 & 74.92 & 88.37 & 59.23 & 169.14 \\
\hline Tetramethylpyrazine & 6.55 & 4.73 & 6.39 & 9.25 & 3.37 & 12.00 \\
\hline 2-Methylpropionic acid & 136.48 & 145.89 & 127.99 & 127.93 & 115.45 & 188.90 \\
\hline 5-Methylfurfural & 56.64 & 76.38 & 70.96 & 73.62 & 49.54 & 132.48 \\
\hline 3-Methylbutyric acid & 448.75 & 507.22 & 465.13 & 451.45 & 413.30 & 685.52 \\
\hline 3-Methylpentanoic acid & 646.24 & 904.65 & 720.57 & 857.35 & 836.10 & 1357.86 \\
\hline$\beta$-Damascenone & 42.26 & 54.00 & 45.11 & 47.91 & 31.76 & 75.10 \\
\hline Megastigmatrienone I & 247.12 & 259.85 & 204.03 & 204.77 & 168.73 & 325.02 \\
\hline Megastigmatrienone II & 628.20 & 617.87 & 535.02 & 530.77 & 423.23 & 775.44 \\
\hline Megastigmatrienone III & 230.05 & 252.21 & 201.49 & 205.75 & 168.10 & 306.82 \\
\hline Megastigmatrienone IV & 764.98 & 796.59 & 653.05 & 667.59 & 572.34 & 991.31 \\
\hline Sclareolide & 59.00 & 73.25 & 61.19 & 54.74 & 59.63 & 94.47 \\
\hline
\end{tabular}

${ }^{a} A$ value of 0.0 indicates that the analyte was below the limit of quantiation.

function of WTPM could possibly be different from the comparisons observed on a per cigarette basis. Thus, all of the concentration data presented previously was normalized to a per mg of WTPM. These values are located in Table 5. As with the previous data a more convenient way to view the data can be found in Figures 9 to 12 .

When normalized to WTPM yields, the trend in compound concentrations established on a per cigarette basis was re-established on a ng/mg WTPM basis. That is, 1) Product $\mathrm{C}$ had consistently the highest levels of pyrazines while Product A was consistently the lowest; 2) methylpyrazine and 2,6-dimethylpyrazine were the dominant pyrazines detected from all products; 3 ) Product E had the highest levels of the targeted carboxylic acids; 4) pyridine, 3-methylpyridine and 3-ethylpyridine were the dominant pyridines detected for all products; 5) Product A was consistently the lowest in pyridines; 6) Product D was consistently the lowest in carotenoid degradation compounds, while Product E was consistently the highest; 7) Product E had the highest levels of furfurals and cyclotene.

\section{CONCLUSION}

A new method has been described as a relatively simple means for providing accurate and precise data on flavorful and important sensory compounds in mainstream tobacco smoke. When applied to the analysis of the electrostatic tube precipitated (ESP) mainstream smoke from five commercially available cigarettes and a University of Kentucky Reference Cigarette, 2R4F, the method was able to detect significant quantitative differences in the mainstream particulate phase amounts of pyrazines, pyridines, furfurals, carboxylic acids, $\beta$-damascenone, sclareolide, and megastigmatrienones. This new quantitative method is based on the gas chromatographic-selected ion monitoringmass spectrometric (GC-SIM-MS) determination of the selected smoke constituents. The accuracy and precision of the approach were well within acceptable parameters having in the majority of cases relative standard deviation (RSD) values consistently around 5\%. Sample preparation was simple requiring only the dissolution of the trapped particulate material in a known volume of methanol 


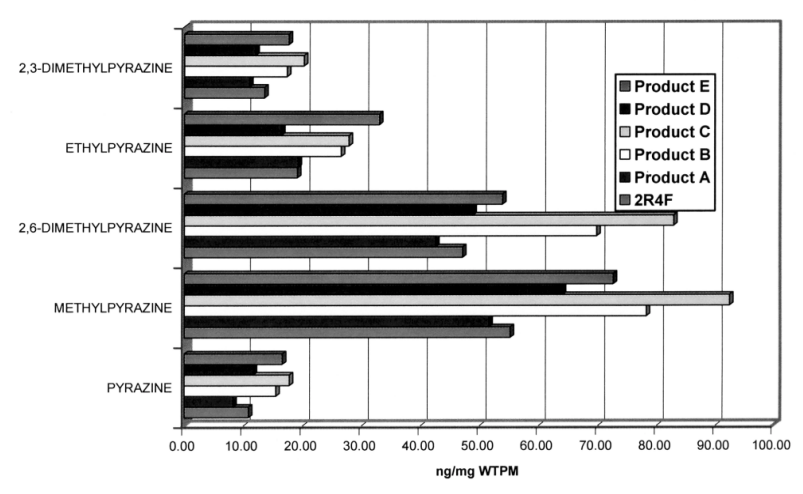

Figure 9. Concentration, ng/mg WTPM, of targeted pyrazines in the mainstream smoke of selected products

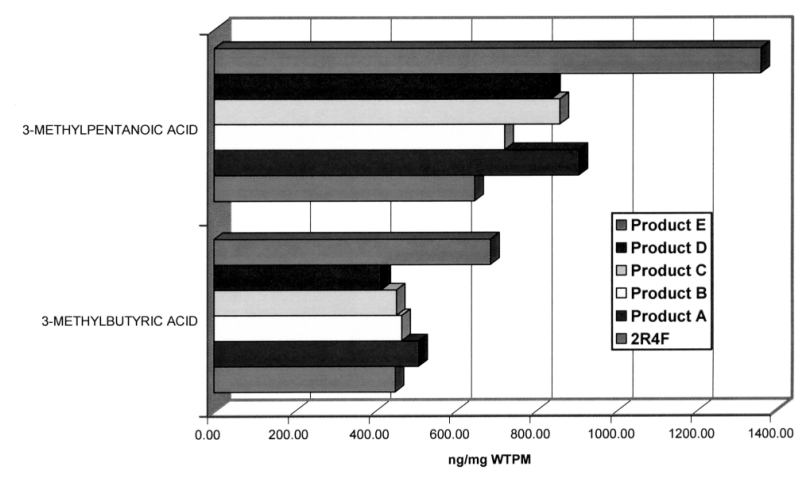

Figure 10. Concentration, $\mathrm{ng} / \mathrm{mg}$ wtpm, of targeted carboxylic acids in the mainstream smoke of selected products

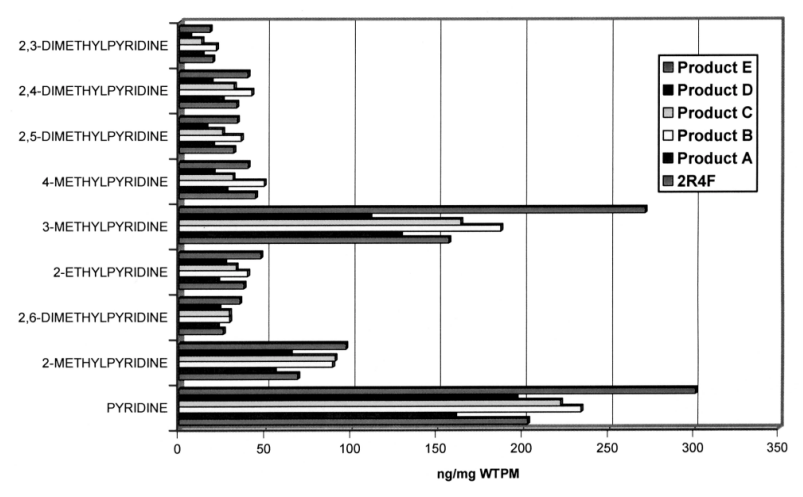

Figure 11. Concentration, $\mathrm{ng} / \mathrm{mg}$ WTPM, of targeted pyridines in the mainstream smoke of selected products

followed by injection of this clear dark colored solution into the gas chromatograph.

After simple sample collection and preparation, the method provides for the quantitative and qualitative evaluation of cigarette products from the perspective of the amount and type of flavor components yielded during burning.

\section{REFERENCES}

1. Green, J.D., J. Chalmers, and P.J. Kinnard: The transfer of tobacco additives to cigarette smoke: Exa-

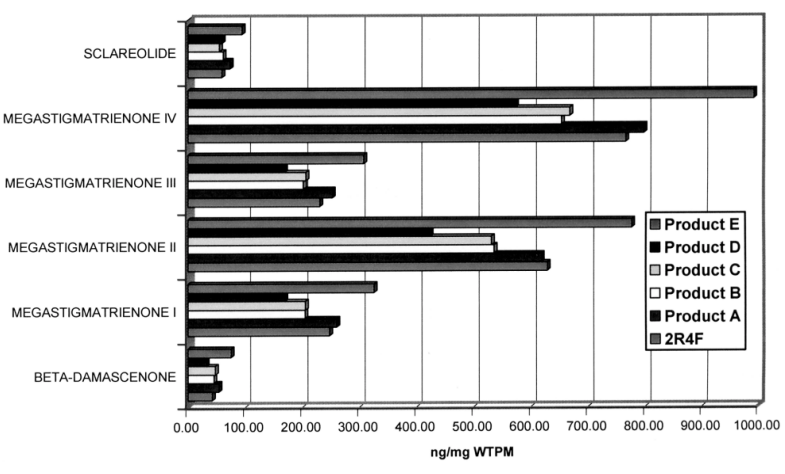

Figure 12. Concentration, ng/mg WTPM, of targeted carotenoid degradation compounds in the mainstream smoke of selected products

mination of the possible contribution of pyrolysis products to mainstream smoke composition; Beitr. Tabakforsch. Int. 14 (1989) 283-288.

2. Carmines, E.L.: Evaluation of the potential effect of ingredients added to cigarettes. Part 1: Cigarette design, testing approach, and review of results; Food Chem. Toxicol. 40 (2002) 77-91.

3. Rustemeier, K., R. Stabbert, H.-J. Haussmann, E. Roemer, and E.L. Carmines: Evaluation of the potential effect of ingredients added to cigarettes. Part 2: Chemical composition of mainstream smoke; Food Chem. Toxicol. 40 (2000) 93-104.

4. Stevens, N.A. and M.F. Borgerding: GC-AED studies of nicotine fate in a burning cigarette; Anal. Chem. 40 (1999) 2179-2185.

5. Paschke, T., G. Scherer, and W.-D. Heller: Effects of ingredients on cigarette smoke composition and biological activity: A literature overview; Beitr. Tabakforsch. Int. 20 (2002) 107-247.

6. Sanders, E.B., A.I. Goldsmith, and J.I. Seeman: A model that distinguishes the pyrolysis of D-glucose, Dfructose, and sucrose from that of cellulose. Application to the understanding of cigarette smoke formation; J. Anal. Appl. Pyrol. 66 (2003) 29-50.

7. Seeman, J.I., M. Dixon, H.-J. Haussmann: Acetaldehyde in mainstream tobacco smoke: Formation and occurrence in smoke and bioavailability in the smoker; Chem. Res. Toxicol. 15 (2002) 1332-1350.

8. Sharma, R.K., J.B. Wooten, V.L. Baliga, P.A. Martoglio-Smith, and M.R. Hajaligol: Characterization of char from the pyrolysis of tobacco; J. Agr. Food Chem. 20 (2002) 771-783.

9. Johnson, W.R., R.W. Hale, S.C Clough, and P.H. Chen: Chemistry of the conversion of nitrate nitrogen to smoke products; Nature 243 (1973) 223-225.

10. Davis, D.L. and M.T. Nielsen: Tobacco Production, Chemistry and Technology; Blackwell Science, Oxford, 1999.

11. Fors, S.: Sensory properties of volatile Maillard reaction products and related products: A literature review; in: The Maillard reaction in foods and nutrition, ACS Symposium Series 215, edited by G.R. Waller and M.S. Feather, American Chemical Society, Washington, DC, 1983, Chapter 12, pp 185-286.

12. Tso, T.C.: Production, physiology, and biochemistry 
of the tobacco plant; Ideals, Inc., Beltsville, MD, 1990.

13. Stevens, N.A. and M.F. Borgerding: Optimization of ${ }^{15} \mathrm{~N}$ detection with an atomic emission detector; Anal. Chem. 71 (1999) 1083-1086.

14. Coleman, W.M., III and H.L. Chung: Pyrolysis GCMS analysis of Amadori compounds derived from selected amino acids and glucose; J. Anal. Appl. Pyrol. 62 (2002) 215-223.

15. Coleman, W.M., III and H.L. Chung: Pyrolysis GCMS analysis of Amadori compounds derived from selected amino acids and rhamnose; J. Anal. Appl. Pyrol. 63 (2002) 349-366.

16. Perfetti, T.A., A.B Norman, B.M. Gordon, W.M. Coleman, III, W.T. Morgan, G.M. Dull, and C.W. Miller: The transfer of nicotine from nicotine salts to mainstream smoke; Beitr. Tabakforsch. Int. 19 (2000) 141-158.

17. Perfetti, T.A. and W.M. Coleman, III: Chiral-gas chromatography-selected ion monitoring-mass selective detection analysis of tobacco materials and tobacco smoke; Beitr. Tabakforsch. Int. 18 (1998) 15-33.

18. Perfetti, T.A., W.M. Coleman, III, and W.S. Smith: Determination of mainstream and sidestream cigarette smoke components for cigarettes of different tobacco types and a set of reference cigarettes; Beitr. Tabakforsch. Int. 18 (1998) 95-113.

19. Coleman, III, W.M., J.L. White, and T.A. Perfetti: Investigation of a unique commonality from a wide range of natural products as viewed from the Maillard reaction perspective; J. Sci. Food Agricol. 70 (1996) 405-412.

20. Shea, J.W.: Federal Trade Commission cigarettes testing for tar and nicotine content; Federal Register 1967: 32; no. $147,1178$.
21. Stedman, R.L.: The chemical composition of tobacco and tobacco smoke; Chem. Rev. 68 (1968) 153-207.

22. Gordon, B.M., M.S. Uhrig, M.F. Borgerding, H.L. Chung, W.M. Coleman, III, J.F. Elder, Jr., J.A. Giles, D.S. Moore, C.E. Rix, and E.L. White: Analysis of fluecured tobacco essential oil by hyphenated analytical techniques; J. Chromatogr. Sci. 28 (1988) 174-180.

23. Buchbauer, G., C.T Klein, B. Wailzer, and P. Wolschann: Threshold-based structure-activity relationships of pyrazines with bell-pepper flavor; J. Agr. Food Chem. 48 (2000) 4273-4275.

24. Coleman, III, W.M. S.N. Lawson: Synthesis of materials rich in pyrazines employing no sugar; J. Sci. Food Agricol. 80 (2000) 1262-1270.

25. Hoffmann, D., and E.L. Wynder: Chemical studies on tobacco smoke, XVIII. Smoke of cigarettes and little cigars: An analytical comparison; Science 178 (1972) 1197-1199.

Address for correspondence

William M. Coleman, III.

R.J. Reynolds Tobacco Company

P.O. Box 1487

Winston-Salem

NC 27102-1487

USA

E-mail: COLEMAW@RJRT.com 